\title{
An Integration and Optimizing Allocation Platform of High Quality Teaching Resources for University-led Collaborative Innovation
}

\author{
Jingzhu $\mathrm{Hu}$ \\ Department of Economics, School of Economics and Management, Beijing Jiaotong \\ University, Beijing 100044, China \\ 11241083@@jtu.edu.cn \\ Abstract
}

\begin{abstract}
Using the theory and method of collaborative innovation, we build an integration and optimizing allocation platform of high quality teaching resources for universities-led collaborative innovation based on the analysis of basiccontent and prooess of university-led collaborative innovation, and study the structure and functions of the platform in detail. Finally we provide a series of effective countermeasures to effectively promote collaborative innovation activities in universities.
\end{abstract}

Keywords: University-led collaborative innovation, High quality teaching resources, Integration and optimizing allocation, Platform

\section{Introduction}

Collaborative innovation is an important strategy choice of China nowadays. 2011, President Jintao Hu proposed the concept of collaborative innovation in his speech in Tsinghua University•Centennial from the perspective of constructing an innovative country, emphasizing that every fnnovation subject of our country should integrate resources according to the strategy need of our country and carry out collaborative innovation activities in order to promote the construction of innovative country. As one of the main subjeets of ellaborative innovation, the university is not only an important base for the cultivation of high-level innovative talents, but also an important source of basic research and high-tech innovations. The collaborative innovation between universities has great significance to comprehensively improve the quality of higher education, implement the innovative capacity enhancement program of universities, promote sound and rapid development of collaborative innovation, especially to promote the mechanism and normalization of collaborative innovation in universities. Therefore, it has become an urgent need to construct an integration and optimizing allocation platform of high quality teaching resources that serves for the collaborative innovation in universities according to the university's resource requirements and following the inherent laws of collaborative innovation in order to ensure the orderly conduct of collaborative innovation activities and improve the performance of the national innovation.

Research abroad on optimal allocation of education resources in universities focuses on the empirical analysis. Such as John f. Ryan [1] by establishing multiple linear regression model to analyze the factors affecting students' graduation rate, puts forward reasonable resource optimization configuration should be leaning to funds allocated to the teaching and scientific research; sinunay-Stern [2], Breu and Raab [3], using DEA method to build model, evaluate the efficiency to optimize allocation of education resources in universities; In addition, there are some scholars use stochastic frontier 
method, statistical classification methods optimize the allocation of education resources. Research starts late in our country, the economics education research, was officially established in the 1980s. Study on this field is focused on the national macrolevel and micro-level of universities. For example Zeng jiarong [4] analyses the nature of higher education resource allocation in the "About the Problem of Optimizing the Allocation of Higher Educational Resources", proposed to foster higher education market with Chinese characteristics. Fan JiXuan [5], Lv Zhaohe [6] and some others discuss the relationship of market mechanism and higher education resources optimization. Addition, there are some scholars study optimized allocation of internal education resources, conflict problems of the resources allocation in universities.

In recent years, in addition to attention to the optimizing allocation of education resources, many scholars began to focus on building a platform of highep education teaching resources, and gradually develop collaborative innovation the ryyin university. For example Meng Na, Long Hamming [7] discuss the desiôn rationality and effectiveness of Yue lu shan University City's higher edducation resources sharing platform, in the "Discussion of Yue lu shan University City teaching resources sharing platform Higher Education". Chen Jin [8] and others proposed industry-university collaborative innovation model, realize the overflow of innovation from the university to the enterprise with technology of university output of knowledge, effectively absorb of companies. Hongzhuan Chen [9], establishes a gray symmetric evolutionary chain model to investigate the stable balance in the process of industry-study-research collaboration innovation. As the main body of collaborative innovation, the university not only needs to complete the efficient alfocation of resources, but also mobilize partnership initiative and creatrvity throughta series of positive measures.

At present, in the process of collaborative innovation between universities, many innovative alliances have built a vanety of high quality teaching resource sharing platforms, which can proyide an effective way for the sharing and interaction of high quality teaching resources between the universities. But in terms of function, most of these platforms just achieve the integration of high quality teaching resources between the universities, they do not have an auxiliary function to facilitate the collaborative innovation between the universities. Meanwhile, they can only realize the resources interaction between søme universities in size, and lack of a comprehensive high quality teaching resources integrating and optimizing allocation service for the innovation development need ot all the country.

Therefore, we intend to use the theory and method of collaborative innovation to analyze the corcept of integration and optimizing allocation of high-quality teaching resource in universities for collaborative innovation, and then build an information platform that meet both the requirements of integration and optimizing allocation of resources and the collaborative innovation in universities. We are going to provide a series of effective countermeasures for related universities and government departments to carry out the collaborative innovation activities.

The organization of this paper is as follows. In Section 2 we introduce the basic content and types of collaborative innovation in universities, and build a system framework for the collaborative innovation in universities; Then, in Section 3, we build an information platform for the integration and optimizing allocation platform of high quality teaching resources in the collaborative innovation of universities; Finally, Section 4 analyzes the operating mechanism of the platform, and provides some suggestions to the relevant universities and government departments. 


\section{Analysis of the Concept and Process of University-led Collaborative Innovation}

\subsection{The Concept of University-led Collaborative Innovation}

Collaborative innovation, which earliest given by Peter Gloria from MIT, is defined as 'a cyber-team of self-motivated people with a collective vision, enabled by the Web to collaborate in achieving a common goal by sharing ideas, information, and work.' [10] And collaborative innovation also can be summarized from the microscopic view as that in order to achieve the common goal, different innovation subjects cooperate, collaborate and consolidate with each other, play to their advantages, obtain external effects, and thus have an effect that 'the total effect of the joint is better thap the sum of individual effect', namely $1+1>2$, thereby reduce the innovation cost and inprove the innovation performance at the same time.

Thus, the university-led collaborative innovation refets to that/according to the important strategic needs of our country or major scientific and technological projects, the disciplines within the universities, the universities, or the teachers in universities and researchers in scientific research institutions put thein superior resources and capabilities in order to solve the crucial and common technolggy problems in industries as well as the major issues in actual productions. Under the collaborative support of government and other related subjects, they tackle key problems for teamwork to seek to make significant progress and breakthroughs in scientific research and technology development.

There are various types of university-led collaborative innovation, so they can use their advantages to carry out innovation activities yith other multi-agents in many fields. For example, according to the gooperation main subject, the university-led collaborative innovation can be divided into the collaboration between universities, the collaboration between university and scientific research institution, the collaboration between international cooperation and so on, according to the purpose of collaboration, the university-led collaborative inovation can be divided into the collaborative innovation of talent cultivation, the collaborative innovatior of technology research and development, the collaborative innovation of discipline Combination and so on; and according to the realization way, the university-led collaborative innovation also can be divided into internal and external collaborative innowation. Here, internal collaborative innovation mainly refers to the collaborative innovation of core elements and a number of supporting elements (such as discipline, teaching, research, administration, teachers and students and so on) associated with it, and simultaneously, external collaborative innovation can cooperate with other research institutes universities and organizations.

\subsection{The Process of University-led Collaborative Innovation}

The core layer of university-led collaborative innovation process is the collaboration of 'Strategy-Resource-Organization', as shown in Figure 1. [11] The collaboration of strategy, organization and resource is a trinity, and they are inter-conditional. They promote each other and have a dialectical and unified relationship. 


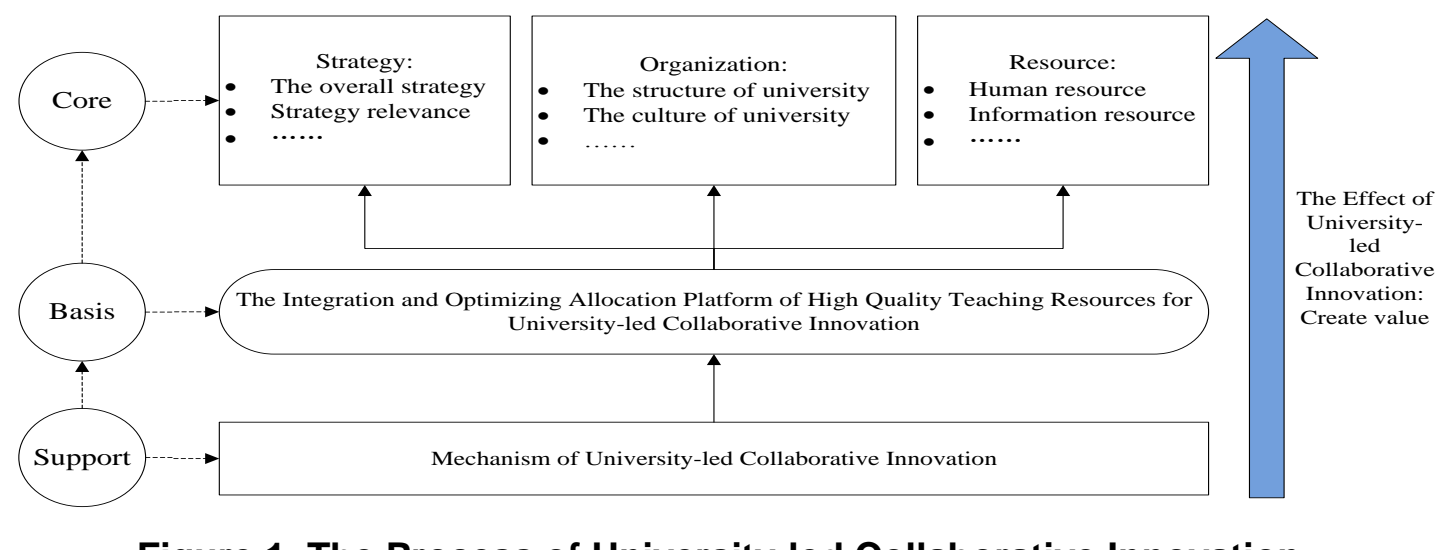

Figure 1. The Process of University-led Collaborative Innovation

(1) Collaboration of Strategy

Collaboration of strategy is the basis. Collaborative innovation between universities requires collaboration of strategy. First, it contains the collaboration of values and culture in universities, followed by the collaboration of vision based on trus and communication, and the third is the collaboration of risk and benefits.

(2) Collaboration of organization

Collaboration of organization is the guarantee Uniyersity-led collaborative innovation involves various main innovation bodies that have different interest objectives. It is a unique hybrid inter-organizational relationship that means a single organization can't get full control of cooperation. Therefore, it needs to have new management skills and organizational design capability, that is to build a cross-border organization at a higher level, such as the specialized collaborative innovation management agency, so that the works of collaborative innovation between universities would have a formal and professional organizational management model.

(3) Collaboration of resource

Collaboration of resource is the core. It is the core of university-led collaborative innovation activities, and it also the transfer, absorption, digestion, sharing, integration, utilization and recreation of high quality teaching resources between universities. It is essentially a process of conversion and upgrade of intangible resources and physical resources that each university owns. Collaboration of resource contains more than one feedbacks and loops. It is astorm-type recombinant of the resource flow among universities.

Hence, the university-led collaborative innovation is a dynamic process, and an effective aggregation of high quality teaching resources and elements in universities. By breaking the barriers between universities, it can fully release their human resource, capital, information, technology and other innovative elements to achieve cooperation deeply. Therefore, to achieve collaborative innovation among universities, we need the support of information platform to promote the effective flow, sharing and integration of various high quality teaching resources in universities.

\section{Integration and Optimizing Allocation Platform of High Quality Teaching Resources for University-led Collaborative Innovation}

\subsection{Architecture of the Platform}

The integration and optimizing allocation platform of high quality teaching resources for university-led collaborative innovation can not only realize the interconnection of existing 
sharing platform of high quality teaching resources among universities, and promote barrierfree flow and collaboration allocation of resources on the collaborative innovation value chain, but also can provide collaborative technical support and service for the further cooperation of university-led collaborative innovation on the basis of integration and optimizing allocation of high quality teaching resources in universities, and thus promote the smooth development of collaborative innovation activities. In other words, the platform should be both an integration and optimizing allocation platform of resources, and also a collaborative innovation work system. Therefore, the design of the platform should be distributive, cooperative and adaptive in order to achieve the interoperability among existing heterogeneous information systems of each university, and realize the cross-system integration and optimizing allocation of high quality teaching resources, and thus effeetively meet the needs of communication and interaction between the suppliers and demanders of high quality teaching resources and promote networking transmission of the yesources for both sides. Meanwhile, according to the resource needs arising from the main innovation subjects during the collaborative innovation cooperation it can provide the required high quality teaching resources and integration services cimely and accurately. Thus, we propose the architecture of the integration and optimizing allocation platform of high quality teaching resources for university-led collaborative innovation, as shown in Figure 2 [12].

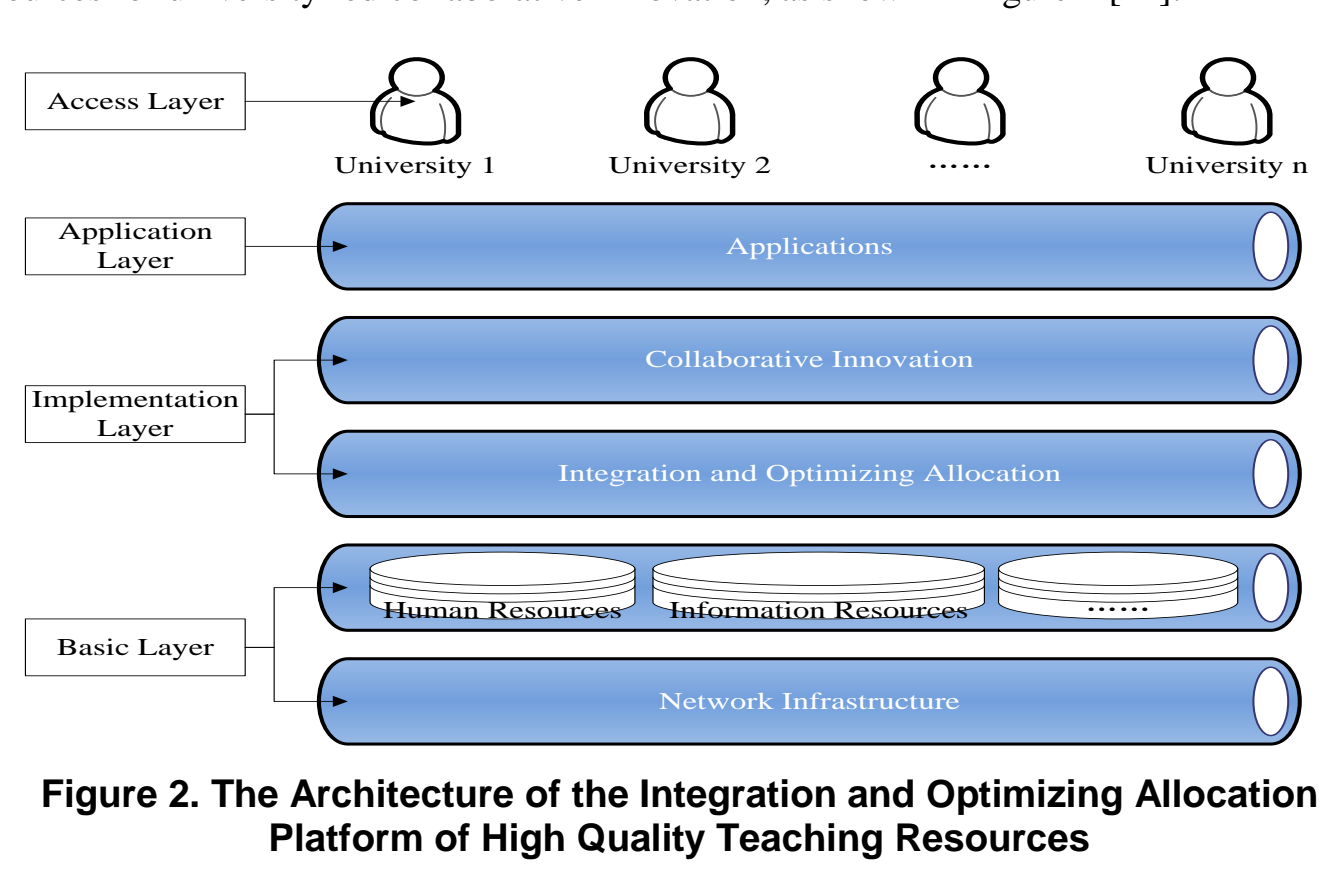

The architecture of the platform is designed according to the design principles of progressiveness, good adaptability to the network environment, unified external data interface, comprehensive data storage, backup management strategy, high security, reliability and stability, ease of operation, flexibility and scalability, component-based software development, and technical data sharing and so on. The entire platform architecture uses a hierarchical and distributed deployment architecture, which is divided into four layers, namely the access layer, application layer, implementation layer and basic layer. It can ensure the consistency and stability of the application service logic, openness of the structure, scalability and maintainability of the function, and the parallelism of the development by separating the application layer and implementation layer. 
(1) Access layer

The users of the platform are mainly the universities. However, they are not just the users of the platform, they are also builders. They need to expand the scope of sharing through resource network, improve the utilization value of the resources under the government's overall planning. During the integration and optimizing allocation process of high quality teaching resources, the universities can use the platform to get the resources they need according to their resource requirements under the supervision of the relevant regulatory agencies.

(2) Application layer

This layer encapsulates the technology and application interface of the layer of integration and optimizing allocation of high quality teaching resources, and provides users integrated services by a unified system interface. This layer includes collaborative innovation platform, high quality teaching resources sharing platform, workflow platform, resource nanagement platform and information service platform.

(3) Implementation layer

This layer is the core of the integration and optimizing allocation platform, which undertakes the task of technical realization of entive integration and optimizing allocation and collaborative innovation work. First, according to the characteristics of distribution, heterogeneity and autonomy, this layer integrates high quatity teaching resources stored in different information systems by means of resource encapsulation, format conversion and data mapping, and establishes a high-level resource Sharing database, in order to provide resource guarantee for collaborative innovation between innovative universities, and then achieves the optimizing allocation of high quatity teaching resources by the functions of description, discovery, optimization, matching and dynamic invocation of high quality teaching resources. Meanwhile, it also provides a unified interaction platform for collaborative innovation among universities, using kinds of collaborative technologies and tool software to service innovation cooperation among universities. The universities can use Web 2.0 and other collaborative communication tools to send instant message, and can also take advantage of the population sensing technology and collaborative control technology to call resources needed for innovation to cooperate, complete the collaborative innovation links via various types of collaborative software, and thus truly realizes the organic combination of integration and optimiging allocation of high quality teaching resources and collaborative innovation.

(4) Basic layer

This layen is the basic condition to support the running of the platform, mainly including the following three aspects, namely the network infrastructure, technical support environment and management mechanism. In addition, it also includes the high quality teaching resources that are distributed stored and other network resources servicing for the integration and optimizing allocation of high quality teaching resource in universities. Due to the heterogeneity of high quality teaching resources, the resource layer needs to apply metadata standard on the unified specification description of these resources, and provides appropriate access interface to metadata and physical data, then uses the Web Service technology to encapsulate data access interface for external systems call.

\subsection{Core Functions of the Platform}

According to the architecture design of integration and optimizing allocation platform of high quality teaching resources, the core functions of the platform are shown in Figure 3.

(1) Resource register and release 
The function of resource register and release aims to achieve the registration management and precise positioning of distributed high quality teaching resources. The universities can describe the information about the resource (such as its name, category, source, property, etc.) by a unified resource description specification. One of the most important parts is the URL that describes position information or WS-Addressing structure, which can facilitate accurate locating and searching of resources. Then the universities can provide registration management and indexing service about the network resources through resource registry meta-service. The function of resource release not only allows the universities to provide their own high quality teaching resources information, but also can release various needs information on the platform, so as to realize the resource cooperation among universities, $\bullet$

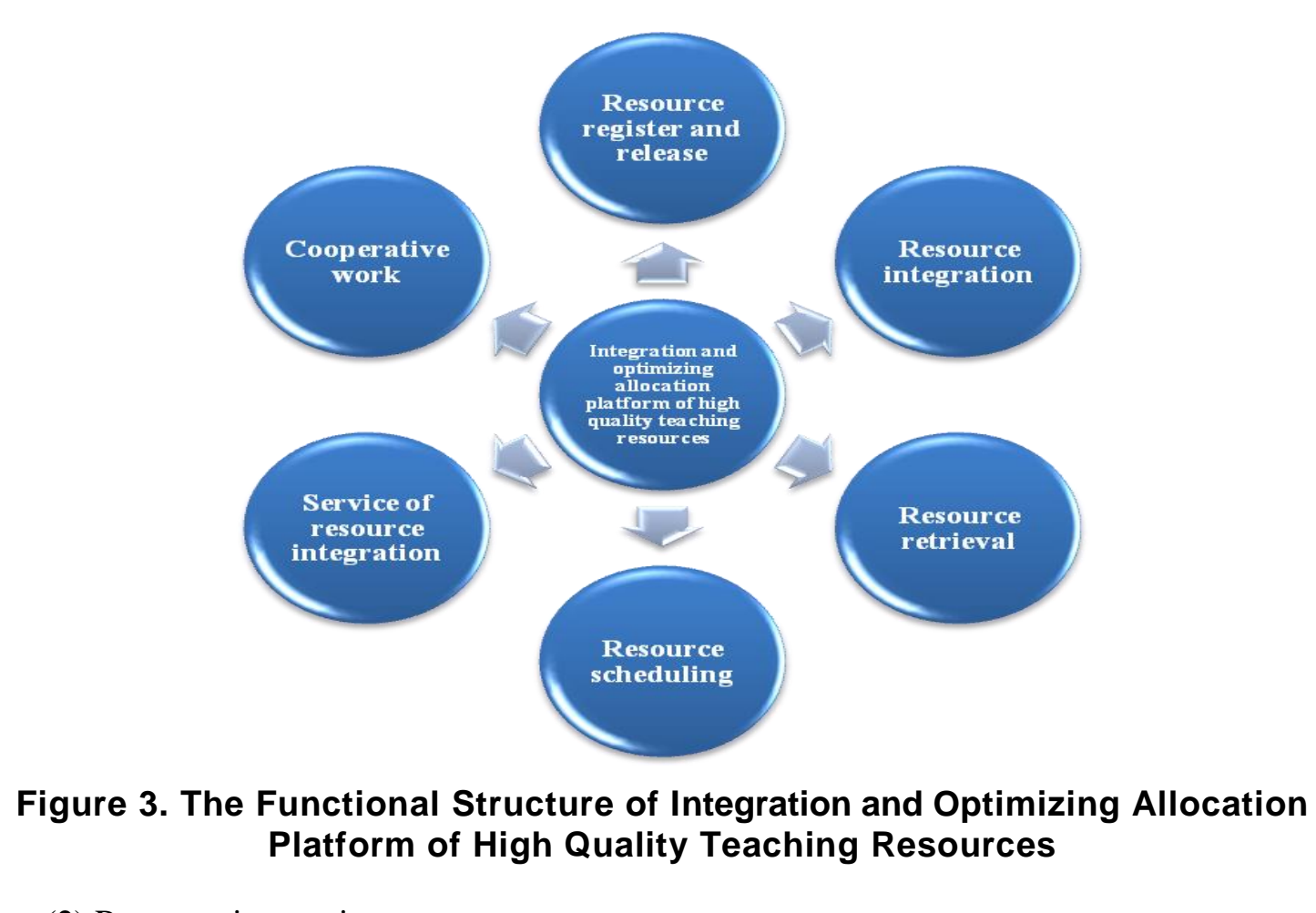

(2) Resource integration

This is one of the main functions of the platform. It aims to realize the integration of distributed high quality teaching resources in different information systems using external coordination technology, middle ware technology, interoperability technology, standard protocol and semantic collaborative, etc. Then establish a data acquisition adapter service system to collect data from different sources, and integrate and classify the integrated resources, and store them in the sharing database. The data then can be used for each university in collaborative innovation activity.

(3) Resource retrieval

The platform provides transparent access to distributed heterogeneous data through data integration and aggregation technology. The user can get access to the integrated high quality teaching resources through keyword matching and semantic search way, etc. Resource retrieval mechanism and aggregation of the allocation of requests and results are the two core issues of resource retrieval. And they can be achieved through resource retrieval agent and service aggregation. Platform can match the user's description of request resource with the description of released resources in order to get a set of resources that meet the needs. 
(4) Resource scheduling

This function can realize dynamic scheduling and allocation of resources using corresponding resource scheduling algorithm. It's generally divided into three stages, namely resource discovery, resource selection and task execution. Here, the resource selection is a key step of scheduling, and it is one of the core features of integration and optimizing allocation platform of high quality teaching resources. The function of resource selection is to choose a reasonable resource collection from a set of available resources according to determined task requirements in order to minimize the task execution time is the shortest. It can maximum satisfy the real-time demand of universities through dynamic resource scheduling and allocation, and thus improve the efficiency of innovation.

(5) Service of resource integration

The service of resource integration includes a series of service functions, such as resource release, process of user feedback, expert system, resource integration and retrîval, resource recommendation, resource navigation, and special advisory setviees, ete. Its main function is to integrate high quality teaching resources and services in universities that distributed in different geographical positions, and then discover, anafyze and call all nleeded resources and services according to the user needs, and finally organize the integrated service in accordance with the personalized service process and business logic flexibly. It can provide one-stop service for universities.

(6) Cooperative work

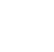

Cooperative work is one of the core functions of the platform. In the environment of the integration and optimizing allocation platform of high quality teaching resources, the universities that distributed in differeht places can realize cooperation about knowledge innovation and technology innovation on this platform using a variety of collaborative software tools (OA, collaborative management software) and collaborative technologies (rolebased collaboration, information cooperation, process collaboration, collaborative technology calculation). The collaborative work manly uses workflow technology to realize the business process running of innoyation subjects, support the centralized control and management of the business processes better, and thus promote the organic interaction between the various links on the innovation value chain effectively.

\section{Policy Suggesfions to Promote the University-led Collaborative Innovation}

In order to implement the "2011 plan", and promote the university-led collaborative innovation actively, the government should encourage the universities to carry out deep cooperation and establish strategic alliance between universities by mechanism innovation and policy guidance. The universities should make collaborative innovation strategy plan according to their own advantage and development orientation, handle the relationship with other universities properly, build collaborative innovation platform actively, establish the talent training zone which stresses top-notch training of innovation talent, and thus build a full range of collaborative innovation environment.

(1) Establish a new concept of collaborative innovation

The university should introduce the concept of collaborative innovation into the practice of talent training, scientific research and social service, highlight the important position of innovation in educational philosophy, and emphasize "cooperation" as an important content of the university running. The university can establish cooperative innovation community that is open, integrated and efficient with scientific research institutes, enterprises, government or other international community around the superior discipline group, meet the needs of 
country, solve the major scientific problems, and thus contribute to the construction of national innovation system.

(2) Optimize the realization form of collaborative innovation

In order to get a formal and professional management model for collaborative innovation, we need to build an effective system of organization and management, including the establishment of a special collaborative innovation management mechanism.

(3) Build a collaborative innovation incentive mechanism

The government department that is relevant should provide security services and policy support for universities. They should consider the input intensity and practical innovation contribution of universities, and then design a reasonable profit distribution scheme in order to encourage and support collaborative innovation.

\section{Conclusions}

To strengthen the integrating and optimizing allocation of high quality telaching resources for cooperative innovation is not only conducive to brean the closed consciousness of each university and improve the utility efficiency of resource, but also/can tap the existing potential of universities, enhance the cooperative innovation concept and innovation ability among them. We analyzed the concept of integration and optimizing allocation of highquality teaching resource for universities-ed collaborative innovation using the theory and method of collaborative innovation, and then buit an information platform that meet both the requirements of integration and optimizing allocation of resources and the collaborative innovation in universities, And finally we provided a series of effective countermeasures for related universities and government departments to carry out the collaborative innovation activities

\section{Acknowledgements}

This work was partally supported by the Quality Improvement Project of Personnel Training of Beijing Municipal Education Commission (No. 03150113016), the grant from the Major Program of Beifing Planning office of Philosophy and Social Science (No. 13ZDB10), and the Course Construction Project of Beijing Institute of Graphic Communication (No. 22150112088).

\section{References}

[1] J. F. Ryan, "The Relationship between Institutional Expenditures and Degree Attainment", Research in Higher Education, vol. 2, no. 45, (2004) March 97-115.

[2] A. Colbert, R. R. Levary, and M. C. Shaner, "Determining the Relative Efficiency of MBA Programs Using DEA. European Journal of Operational Research”, vol. 125, (2000), pp. 656-669.

[3] T. M. Beru and R. L. Raab, "Efficiency and Perceived Quality of the Nations 'TOP25' National Universities and National Liberal Arts Colleges: An Application of Data Envelopment Analysis to Higher Education", Socio-Economic Planning Science, vol. 28, (1994), pp. 33-45

[4] Z. J. Rong, "About the Problem of Optimizing the Allocation of Higher Educational Resources", Journal of Southwest Jiatong University (Social Sciences), vol. 1, (2003), pp. 12-16.

[5] F. Ji Xuan, "Optimize the allocation of the higher education resources in popular early stage of China", Exploring Education Development, vol. 9, (2005), pp. 37-41.

[6] L. Z. He, "Economic analysis of Chinese optimize the allocation of higher education resources", Journal of Hebei University of Science and Techno logy (Social Sciences), vol. 6, (2002), pp. 45-50.

[7] M. Na and L. H. Ming, "Discussion of Yue lu shan University City teaching resources sharing platform Higher Education", Times Finance, vol. 2, (2009). 
[8] J. Chen and W. Ye, "The modes of university-industry collaborative innovation in service: A case study from China", Proceedings of the 4th IEEE International Conference on Management and Service Science, (2010), pp. 1471-1475, Wuhan University, Wuhan

[9] H. Chen, Q. Zhao and Z. Jin, "Study on grey evolutionary Game of "Industry-University-Institute" Cooperative Innovation", Proceedings of 2009 IEEE International Conference on Grey Systems and Intelligent Services, (2009), pp. 1120-1125, Nanjing University of Aeronautics and Astronautics, Nanjing

[10] Z. Li and C. Liang, "Exploration on the Cooperative Innovation Mechanism-Base on the perspective of university”, China Higher Education Research, vol. 7, (2012), pp. 81-84.

[11] Y. He, "The theoretical model of I - U - R collaborative innovation", Studies in Science of Science, vol. 2, no. 30, (2012) February, pp. 165-174

[12] Y. Zhao and K. Lv, "Construction and Implementation of Information Resources Allocation System for Collaborative Innovation”, Information Science, vol. 9, no. 31, (2013), September 15-19.

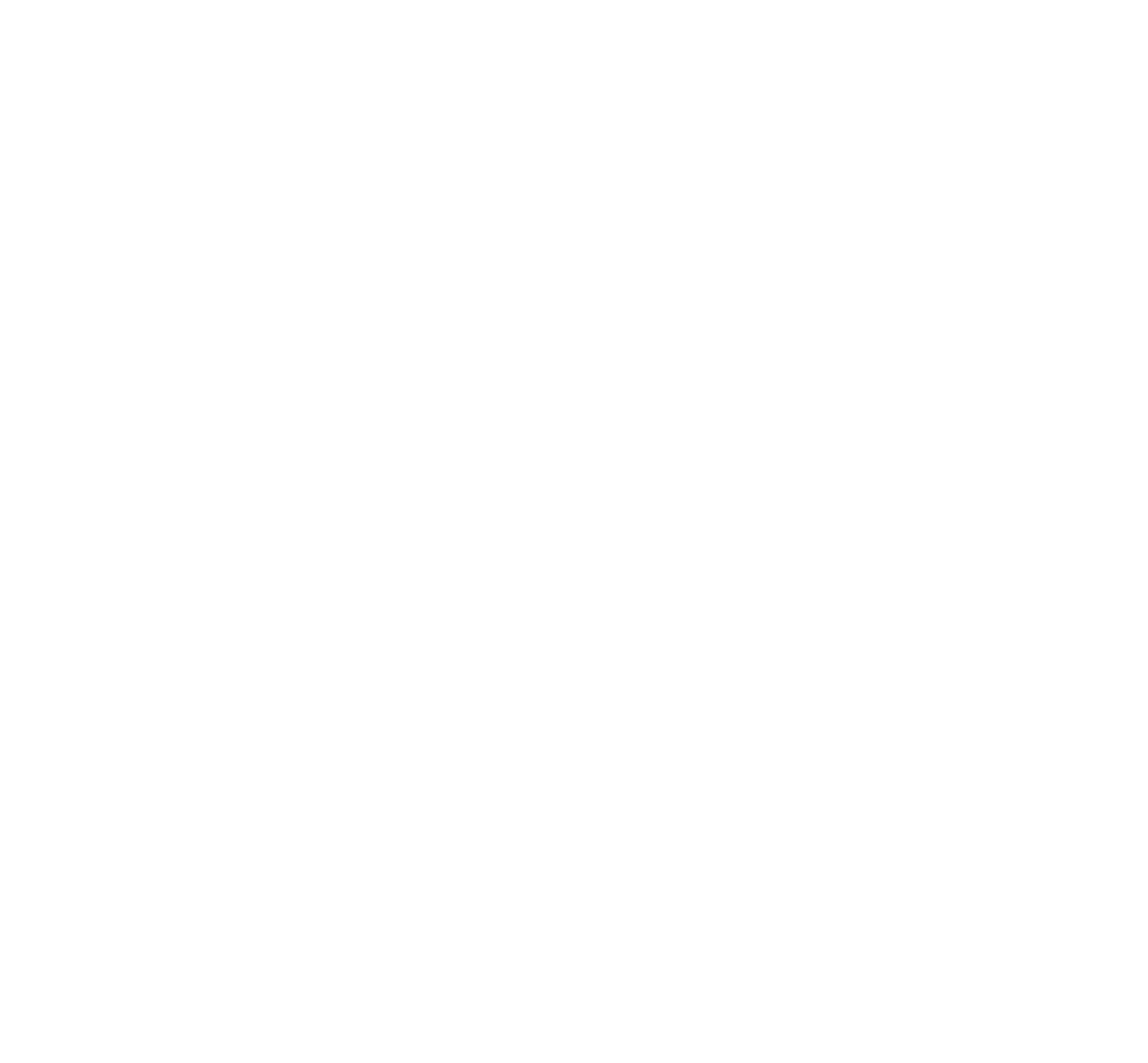

